\title{
Stevioside as A low caloric sweetener to milky drink and its protective role against oxidative stress in diabetic rats
}

\author{
Ayman M. Badawi*, Nadia A. El-tablawy*, Nahed S. Bassily** \\ Sami A. El-Behairy*** \\ * Department of Biochemistry, ** Department of Histology, \\ *** Department of Food Evaluation and Food Science \\ National Organization For Drug Control And Research (NODCAR) \\ P.O. Box 29, Cairo, Egypt.
}

\begin{abstract}
Stevioside is a natural sweetener extract from the plant Stevia rebaudiana Bertoni. Stevioside was used in traditional medicine among Indian community in Brazil for the treatment of diabetes. The present study aimed to investigate the safety of stevioside as natural sweetener substitute sugar in a dairy product needed by those suffering from diabetes and its protctive role against oxidative stress exerted by hyperglycemia.

The antibacterial activity of stevioside showed no effect on the pathogenic bacteria namely $S$. aureus, $S$. typhomuium and $E$. coli as well as lactic acid bacteria. In the present study hyperglycemia was induced by i.p. injection of alloxan in two successive doses $(70 \mathrm{mg} / \mathrm{kg} \mathrm{b} . \mathrm{w}$. eash / day to rats preadministered stevioside in two different doses $(640 \mathrm{mg} / \mathrm{kg}$ b.w. and 1.280 $\mathrm{g} / \mathrm{kg}$ b.w.) for eight weeks.

The following investigations were carried out, glucose tolerance test, blood glucose, blood glutathione, MDA, erythrocyte SOD and transminases. The histopathological examinations were performed at the end of the experimental period. The results obtained in this study assessed the safety and protective role of stevioside as a natural sweetener substitute sugar in a dairy product.
\end{abstract}

\section{Introduction}

Stevia (Asteraceae) is a woody shrub that can reach $80 \mathrm{~cm}$ in height when it is fully matured. The stevia genus comprises at least 110 species (Rajbhandari and Roberts, 1983). Different species of stevia contain several potential sweetening compounds, with stevia rebaudiana Bertoni being the sweetest of all (Soejarto et al., 1982 and Kinghorn et al., 1984).

The complete chemical composition of stevia species is not yet completely available. However, a variety of stevia species have been tested to their chemical composition. The useful part of this shrub is the leaves Out of 100 species tested for sweetness, only 18 were found to possess this characteristics (Soejarto et al., 1982). Eight entkaurene glycosides namely ducloside A, rebaudiosides A-E, steviolbioside and stevioside, produce the sweet taste sensation (Kinghorn et al., 1984). According to Melis, (1992) and Shibata et al., (1995) stevia Rebaudiana Bertoni, the sweetest species, contains in its leaves all the eight ent-kaurene glycoside with stevioside being the major constituent (3-8\% by weight of the dried leaves)

Stevia is used in many parts of the world as a low caloric sweetener. Stevioside is 300 times sweeter than sucrose (Matsui et al., 1996 and Maier et al., 2003).

Many investigators have shown that the administration of stevioside leads to antihyperglycemic effects by enhancing not only insulin secretion, but also insulin utilization in insulindeficient rats (Suzuki et al., 1977; Soejarto, et al., 1982; Jeppesen et al., 2003; Gregersen et al., 2004 and Chen et al., 2005).

Oxidative stress is caused by a relative overload of oxidants i.e. reactive oxygen species. This impairs cellular functions and contributes to the pathophysiology of many diseases. Evidence have accumulated suggesting that diabetic patients are under oxidative stress and that complications of diabetes seem to be partially mediated by oxidative stress 
(Hayoz et al., 1998; Rosen et al., 1998 and Szaleczky et al., 1999).

Yinic et al., 1998 proved that stevia rebaudiana leaves extract effectively inhibited hydroperoxide and volatile component formation in sardine oil. The oxidation was more effectively inhibited by the hot water extract from leaves of stevia rebaudiana than DL- $\alpha$-tocopherol or green tea extract at the same concentration in sardine oil.

The demand for functional food is growing rapidly all over the world due to the increased awareness of the consumer on the impact of food on health (Stoon 2002).

Low sugar dairy products represent an important category of functional product, needed by those suffering from diabetes, obesity and those watching their weight.

This study is aimed to evaluate the safety use of stevioside as a low caloric sugar substitute, as well as its protective role on hyperglycemic rats and the toxic effects induced by alloxan in experimental animals.

\section{Materials and Methods \\ Materials: \\ Skim milk powder:}

Skim milk powder was obtained from

Misr Dairy and Food Company, Egypt.

Yoghurt culture:

Commercial freeze dried culture which consists of lyphylized of Streptococcus thermophilus and Lactobacillus bulgaricus was obtained from Microbiological Resource (T.G. Centre Cairo Mircen-Egypt).

Bacterial strains:

Staphylococcus aureus (CAIM 1803), Escherichia coli (CAIM-1357), Salmonella typhimurium (Caim 1350), were kindly supplied by Microbiological resource (T.G. Centre Cairo Micron-Egypt),

Pure strains belonging to Lactobacillus bulgaricus ATCC 11942 and Streptococcus thermophilus NCTC 7161 were provided by Microbiological Resources (T.G. Centre Cairo Mircen- Egypt).

Stevioside:

Stevioside was obtained from JA3A stevioside TM, USA, which contain 95.25\% stevioside compound.
Alloxan monohydrate was obtained as all the other chemicals from Sigma Chemical Co., St. Louis, Mo., USA.

Methods:

Detection of stevioside effect on bacterial growth:

Nutrient broth fortified with stevioside at the level of 6.5 and $13 \mathrm{mg} / \mathrm{mL}$ were inoculated with pure strains of L. bulgaicus and Str. Thermophilus, microbial growth after $24 \mathrm{hrs}$ incubation was detected.

Similarly fortified nutrient broth with stevioside was inoculated with some pathogenic bacteria namely Staph. aureus, E. coli and Salmonella, the growth were detec-ted by the same way mentioned before.

Reconstituted skim milk was fortified with stevioside (after autoclaving), at the level of 6.5 and $13 \mathrm{mg} / \mathrm{ml}$. The sterilized skim milk incorporated with stevioside was inoculated separately with $3 \%$ yoghurt culture of Streptococcus thermophilus and L. bulgaricus and incubated at $37^{\circ} \mathrm{C}$ for $24 \mathrm{hr}$.

\section{Disc method:}

This method was carried out according to Collins et al. (1989).

Determination of milk clotting time:

The time necessary for the formation of curd was measured in the fortified skim milk with stevioside $(6.5 \& 13 \mathrm{mg} / \mathrm{mL})$ at interval periods up to $4 \mathrm{hrs}$ by using yoghurt culture.

\section{Induction of hyperglycaemia:}

1- The effect on glucose load (glucose tolerance test, GTT): An oral glucose load equivalent to $2.5 \mathrm{gm} / \mathrm{kg}$ b.w. (Madkour et al., 1977) was administered to adult male albino rats. The animals were previously fasted for 18 hours before the initial fasting level and glucose load.

2- Diabetes mellitus was induced by alloxan injection i.p.(two doses of 70 $\mathrm{mg} / \mathrm{kg}$ b.w. with a 24-hour interval) according to Raskovic et al. (2004).

\section{Animals and experimental design:}

A total of 80 adult male albino rats weighing about 130-150 were used in two separated experiments in order to study the prophylactic effect of stevioside against 
glucose load (glucose tolerance test, GTT) and alloxan induced hyperglycemia.

Experiment-I: Effect of pretreatment with steviosid on glucose load (glucose tolerance test, GTT):

A total of 32 animals were used in this experiment and were divided randomly into equal four groups (8 rats each). The first group served as control (group1) and the other three groups were subjected to manipulate as follows:

Group ( $2 \&$ 3): Rats were received stev-1 $(640 \mathrm{mg} / \mathrm{kg}$ b.w.) and stev-2 (1280 mg/kg b.w) dissolved in skim milk and mixed with basal diet for 8 weeks, then orally administrated with glucose load $(2.5 \mathrm{~g} / \mathrm{kg}$ b.w.).

Group (4): Rats were orally administrated a single dose of glucose $(2.5 \mathrm{~g} / \mathrm{kg} / \mathrm{b} . \mathrm{w}$.) (Madkour et al., 1977)

The blood samples were collected before glucose load and after 1,2 and 3 hrs for the determination of blood glucose.

Experiment-II: The protective effect of stevioside against alloxan induced hyperglycemia

In this experiment, 48 rats were used and divided randomly into equal three groups (16 rats each). The first group was designated as a control group. Group two received a low daily dose of stevioside (640 $\mathrm{mg} / \mathrm{kg}$ b.w.) dissolved in skim milk and mixed with basal diet and this group was designated as stevioside (1) group. Group three received a high daily dose of stevioside $(1280 \mathrm{mg} / \mathrm{kg}$ b.w.) dissolved in skim milk and mixed with basal diet and this group designated as stevioside (2) group. The two previous doses are equivalent to $1 / 20$ and $1 / 10$ of the LD50 (Toskulko et al., 1997).

Induction of hyperglycemia; after eight weeks from stevioside (1) and (2) administration, the rats were treated with alloxan (i.p. in two successive doses 70 $\mathrm{mg} / \mathrm{kg}$ b.wt each / day). according to Raskovic et al. (2004). The blood samples were collected at 0,4 and 8 weeks during stevioside treatments and also after 8 weeks after the induction of hyperglycemia.

At the end of the exsperimental period histopological examination was carried out for liver, kidney and pancreas to evaluate the effects of stevioside in normal and diabetic rats.

\section{Biochemical analysis:}

Venous blood samples (2 $\mathrm{ml}$ from each rat) were collected in heparinized tube from retro-orbital veins. Plasma samples were separated and subjected to the subsequent biochemical analysis: Glucose (Trinder, 1969), transaminases, ALT \& AST (Reitman and Frankel, 1957), malondialdehyde, MDA (Buege and Aust, 1978), hemoglobin, $\mathrm{Hb}$ (Van Kampen and Zijlstra, 1967), reduced glutathione in whole blood, GSH (Beutler et al., 1963) and superoxide dismutase, SOD (Marklund and Marklund, 1974).

\section{Statistical Analysis:}

The data obtained were performed and statistically analyzed by t-test according to the method described by (Bernstein and Weatheral, 1952).

\section{Results and Discussion}

To achieve the goal of this study the obtained results may be conveniently described and discussed under the following topics:

\section{I- The antibacterial activity:}

1-1. Effect of different concentrations of Stevioside on the growth of studied bacteria:

In respect of the effect of stevioside at the level of concentrations $(6.5 \& 13 \mathrm{mg} / \mathrm{ml})$ on the growth of pathogenic bacteria, in nutrient broth. Pure strains of E. coli, Staph. auerus and Salmonella in the presence of the natural sweetener were used. Data in Table (1) revealed that the stevioside had no effect on the growth of pathogenic bacteria by using tube method or disc method.

Similar trend of results were noticed by using pure strains of L. bulgaricus and Str. Thermophilus in the presence of the two concentrations used (Table 1), by the two ways mentioned before.

Data concerning the effect of different concentrations of the natural sweetener on the growth of starter, (3\%) (Str. Thermophilus and L. bulgaricus) are shown in 


\section{Stevioside as A low caloric sweetener to............}

Table (2). High concentration used had no effect on bacterial growth and normal clotting was observed (Table 2).

The obtained data of the herein study were disagreement with that obtained by Tomita et al., (1997) who reported that a fermented aqueous extract from stevia rebandiania showed strong bactericidal activity towards a wide range of food born pathogenic bacteria including hemorrhage Escherichia coli. Anonymous (1980) Barry and Henry (1981) found that stevioside was a less favourable substrate for Streptococcus mutans, they reported that Stevia rebaudiana was found to be active against several bacterial species specially against pseudomonas aeruginosa and Proteus valgaris.

Difference concerning the activity of stevioside on our study compared to the others may be due to the variation in concentrations of stevioside and the species used. The neutral effect of stevioside on lactic acid bacteria may be due to that stevia dry matter and its aqueous extract contain different levels of nutritionally important microelements which are zinc, magnesium, selenium, these results indicate that the richness of stevia with essential elements are needed for the growth of lactic acid bacteria.

\section{2- Biochemical studies:}

The natural sweetener stevioside, which is found in the plant stevia Rebaudiana Bertoni has been used for many years in the treatment of diabetes among Indians in Paraguay and Brazil (Jeppesen et al., 2000).

\subsection{Protective role of stevioside as low caloric sweetener added to milk mixed with basal diet on glucose level:}

The data in Figure (1) revealed that, the preadministration of stevioside reduced the rise in blood glucose level during glucose tolerance test, with respect to the control non stevioside preadministated rats. These results were in agreement with those obtained by Jeppesen et al., (2002) and Chen et al., (2005). They reported that, stevioside regulate blood glucose level by enhancing not only insulin secretion but also insulin utilization in insulin deficient rats.

As can be seen from Figure (2) the administration of basal diet mixed with milk sweated with stevioside (1) or (2), to the experimental animals for eight weeks had no effect on blood glucose level as compared with the control group. Meanwhile, after the induction of hyperglycemia (by alloxane injection) the group of rats that not subjected to the preadministration of stevioside (1) or (2) showed a very highly significant $(\mathrm{P}<0.001)$ increase in the blood glucose level (Diabetic control group). The preadministration of both stevioside (1) and (2) caused a less drastic effect in the level of blood glucose with a very highly significant decrease $(\mathrm{P}<0.001)$ with percent decrease 56 and 52\%, respectively, compared with the diabetic control group. Curi et al., (1986) showed that the oral intake of stevia rebaudiana Berotni extract for 3 days slightly suppressed plasma glucose during an oral glucose tolerance test in healthy subject. Gregersen et al., (1996), Jeppesen et al., (2003) and Gregersen et al. (2004) demonstrated that, both intervenous and oral administration of stevia extract exert antihyperglycemic, insulinotropic and glucago-nstatic action in the mild type 2 diabetes.

The data obtained in this investigation definitely proved that the preadministration of stevioside, as natural product sugar substitute, displayed a well marked reduction in the glucose level induced by alloxan.

\section{2-2. Antioxidant effect of stevioside:}

The data depicted in Figure (3) revealed that the administration of stevioside (1) and (2) as sugar substitute for eight weeks caused no change in the level of plasma MDA. The induction of experimental hyperglycemia caused a well marked increase $(\mathrm{P}<0.001)$ with a $54 \%$ change in the level of plasma MDA (as compared with the normal level ). Meanwhile the preadministration of stevioside in a low dose (stevioside 1) and high dose (stevioside 2) caused a marked change in the level of plasma with $17.8 \%$ increase and $34.8 \%$ as compared with the non treated rats. Meanwhile the preadminist- 
ration of stevioside (1) and (2) caused a very highly significant $(\mathrm{P}<0.001)$ and highly significant decrease $(\mathrm{P}<0.01)$ in the MDA level in comparison with the diabetic control group.

From the prementioned results, the preadministration of stevioside exert a protective effect on lipid peroxide in a dose dependant manner.

As can be seen from Figure (4) the preadministration of stevioside (1) and (2) for eight weeks had no effect on the level of glutathione in the whole blood. The figure also showed that, the induction of hyperglycemia caused a very highly significant decrease $(\mathrm{P}<0.001)$ in the level of blood glutathion with a $46 \%$ in comparison with non diabetic rats. Meanwhile, the preadministration of stevioside (1) and (2) caused insignificant change $(\mathrm{P}>0.05)$ on the whole blood glutathione level in comparison with non diabetic control group. The data obtained in this investigation assessed the protective effect of stevioside (1) and (2) administration.

Figure (5) illustrated that, the induction of hyperglycemia caused a $35 \%$ increase in the level of erythrocyte superoxide dismatase activity. The preadministration of stevioside (1) and (2) displayed a limited decrease in the enzymatic activity level with respect to the diabetic rats. It has been documented that impaired homeostasis in diabetes is associated with increased production of reactive oxygen species and depletion of oxidant defence system which may be due to the damage of beta cells (Sabu and Kuttan 2004, El-Alfy et al., 2005 and Gumieniczek, 2005). The present study clarified the protective role of stevioside as a natural sweetener against free radical exerted by alloxan induced hyperglycemia. The results obtained in this study proved that, the administration of stevioside was effective in maintaining the normal level of reduced glutathione in the whole blood (Lee, 1979; Yadav et al., 1997 and Dincer et al. 2002) as ameliorating the increase which obtained in both lipid peroxide and superoxide dismutase activity.

\section{2-3. Protective role of stevioside} administration on liver transaminases:

Figure (6) revealed that, the administration of stevioside (1) and (2) for eight weeks had no effect on transaminases activity with respect to non stevioside rats.

It may be pointed out that the inducton of hyperglycemia caused a well marked increase in the level of both ALT and AST activity in non stevioside administration group. As can be seen from the figure the stevioside preadministration exert non significant increase $(\mathrm{P}>0.05)$ in level of transaminases. The result obtained in this category were confirmed by the histopathological examination.

\section{3- Histological examination:}

\section{3-I, Histopathological examination of liver:}

In animals treated with low or high dose of stevioside for 8 weeks duration liver tissue revealed normal lobular architecture with normal hepatocytes architecture. Mild dilation in the central and portal veins were seen in areas together with mild lymphocytic infiltration. However, in animals treated with the high dose of stevioside, focal mild vacuolated hepatocytes were seen scattered predominantly in subcapsular area and at the periphery of few hepatic lobules (Fig. 7).

In animals received alloxan (diabetic group), microscopical examination of liver tissue showed diffuse, marked vacuolar degenerative changes of hepatocytes with atrophid vacuolar degenerative changes of hepatocytes with atrophid nuclei. Dilated portal and central veins were seen in areas (Fig. 8).

The forementioned changes to be compared with the changes that occurred in diabetic groups of animals received stevioside where examination of hepatic tissue which revealed scattered diabetic and congested central and hepatic portal veins, with mild mononuclear inflammatory cells infiltrate in the portal areas. Evidence of libel ductile proliferation, and thickened hyalinized wall of arterioles were detected in 


\section{Stevioside as A low caloric sweetener to............}

diabetic animals received low or high dose of stevioside (Fig.9). Whereas areas of vaculated hepatocytes were seen only in diabetic animals received the high dose.

\section{3-2. Histopathological examination of kidney:}

In animals treated with stevioside for 8 weeks duration, low or high doses, kidney tissue showed normal appearing glomeruli, renal tubules, interstitial tissue and vasculature.

In diabetic group of animals, microscopical examination of kidney tissue revealed, vacular degenerative changes of the lining renal tubular epithelium together with dilatation in some tubules (Fig. 10). Focal glomeruliosclerotic changes were detected in areas (Fig. 11), while thickened hyalinized walls of arterioles were occasionally seen.

When induction of diabetes was performed on groups of animals pretreated with either low or high dose of stevioside, microscopical examination of kidney tissue revealed scattered groups of mild dilated proximal rend tubules, with evidence of mild vacular degenerative changes of their lining epithelial cells. Mild scattered inflammatory cells infiltrate were seen in interstitial tissue and foci of extravasated R.B.Cs. Focal glomerulosclerotic changes could be detected however less frequent than in diabetic group (Fig. 12).

\section{3-2. Histopathological examination of pancreas:}

In animals treated with low or high dose of stevioside, for 8 weeks duration, normal appearing size, number, and cellularity of pancreatic islets and acini were seen
(Fig.13 a,b). Where as in diabetic group of animals (positive control), histopathological examination of pancreatic tissue revealed marked reduction in number, size and cellularity in most pancreatic islets, this was accompanied with focal inflammatory cells infiltrate and acidophilic hyaline material deposited between acini (Fig. 14).

In diabetic induced group of animals, pretreated for 8 weeks with low or high doses of stevioside, microscopical examination of pancreas showed reduction in number, size and cellularity in $50 \%$ of the examined pancreatic islets (Fig. 15).

In general, the improvement was more pronounced in animals treated with the high dose of stevioside. In addition to the forementioned change, focal inflammatory cells infiltrates were seen and mild thickening with hyalinization in wall of small arterioles.

The obtained data concerning the Histopathological examination of liver was in agreement with Hubler et. al., (1994) who reported that stevioside increased the initial glycogen deposition in the liver which may explain the hepatocytes vacuolation seen in the herein study.

The histopathological examination of kidney tissue is in correlation with that obtained by Toskulkao et al., (1997) who stated that stevioside caused severe degeneration of the proximal tubular cells.

The pronounced improvement of the histological appearance of pancreatic islets noticed in the present work, may explain the result obtained by Jeppesen et al., (2000), who clarified the insulinotropic effects.

Table (1): Effect of stevioside on the growth of studied bacteria

\begin{tabular}{|l|c|c|c|c|c|c|}
\hline \multirow{2}{*}{ Test organism } & \multicolumn{7}{|c|}{ stevioside (mg/ml) } \\
\cline { 2 - 7 } & \multicolumn{3}{|c|}{ Tube method } & \multicolumn{3}{c|}{ Disc method } \\
\cline { 2 - 7 } & Control & 6.5 & 13 & Control & 6.5 & 13 \\
\hline S. aureus & +++ & +++ & +++ & 0 & 0 & 0 \\
\hline E. coli & +++ & +++ & +++ & 0 & 0 & 0 \\
\hline S. typhimurum & +++ & +++ & +++ & 0 & 0 & 0 \\
\hline L.bulgaricus & +++ & +++ & +++ & 0 & 0 & 0 \\
\hline Str.thermophilus & +++ & +++ & +++ & 0 & 0 & 0 \\
\hline
\end{tabular}


Table (2): Effect of adding stevioside to skim milk on clotting time.

\begin{tabular}{|l|c|c|c|c|}
\hline \multirow{2}{*}{ Stevieside concentration $(\mathrm{mg} / \mathrm{ml})$} & \multicolumn{4}{|c|}{ Clotting time / hr. } \\
\cline { 2 - 5 } & 1 & 2 & 3 & 4 \\
\hline Control & - & - & - & + \\
\hline 6.5 & - & - & - & + \\
\hline 13 & - & - & - & + \\
\hline
\end{tabular}

Control : without stevioside

$+=$ Clotting within $4 \mathrm{hr}$.

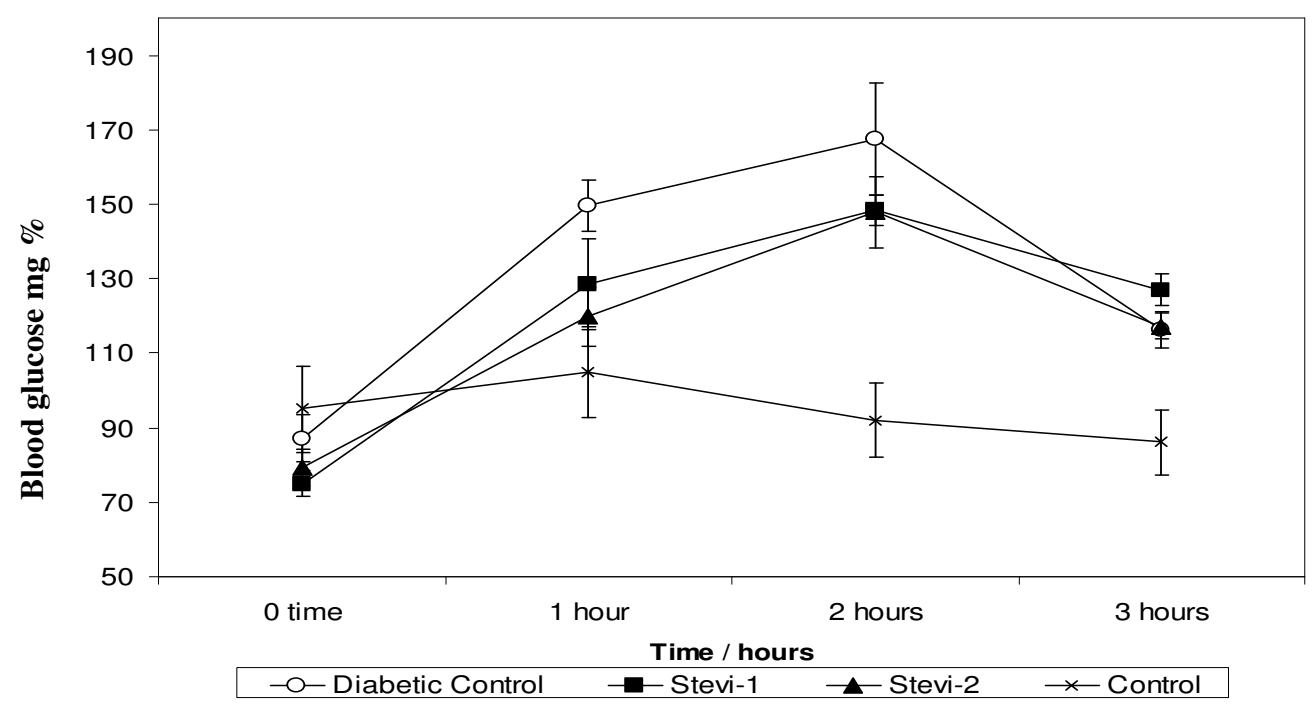

Fig.(1): The Effect of pretreated with Stevioside on Blood glucose (glucose tolerance testing, GTT).

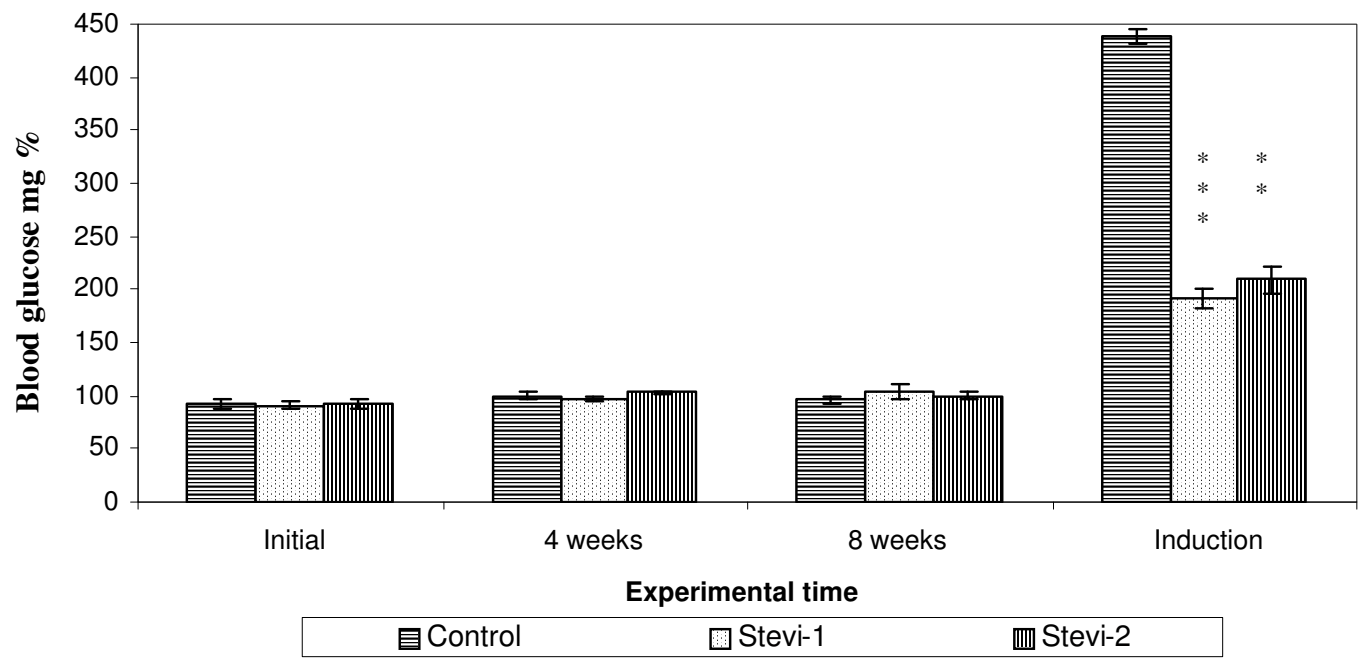

Fig.(2): The prophylactic Effect of pretreated Stevioside on Blood glucose $\mathrm{mg} / \mathrm{dl}$ for 8 weeks and after hyperglycemia induction.

*** very highly significant difference for hyperglycemic control corresponding to normal initial level at $\mathrm{P}<0.001$

*** very highly significant difference for treatments corresponding to hyperglycemic level at $\mathrm{P}<0.001$

** highly significant difference for treatments corresponding to hyperglycemic level at $\mathrm{P}<0.01$ 


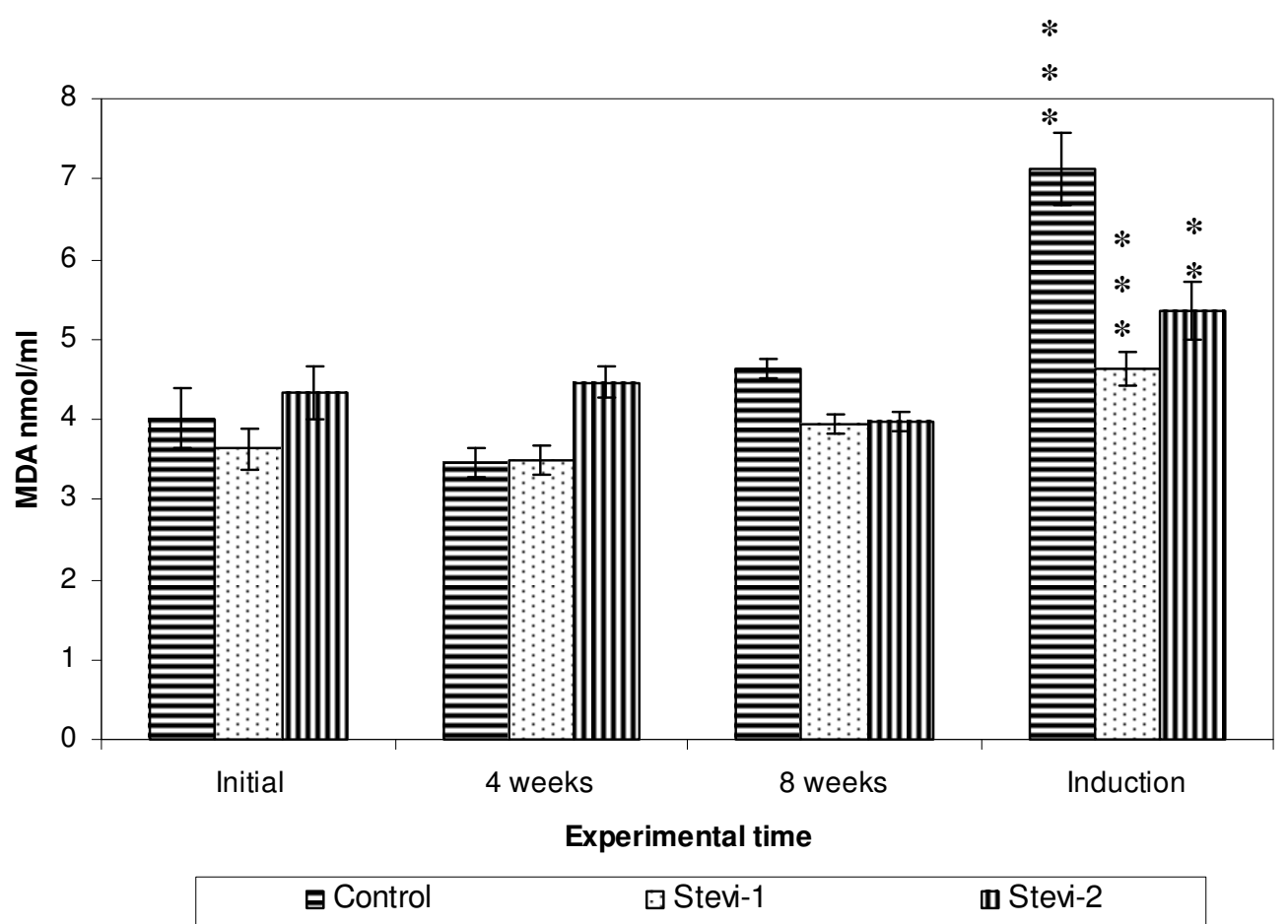

Fig.(3): The protective effect of stevioside preadministation for 8 weeks on malondialdehyde (MDA) and after the induction of hyperglycemia.

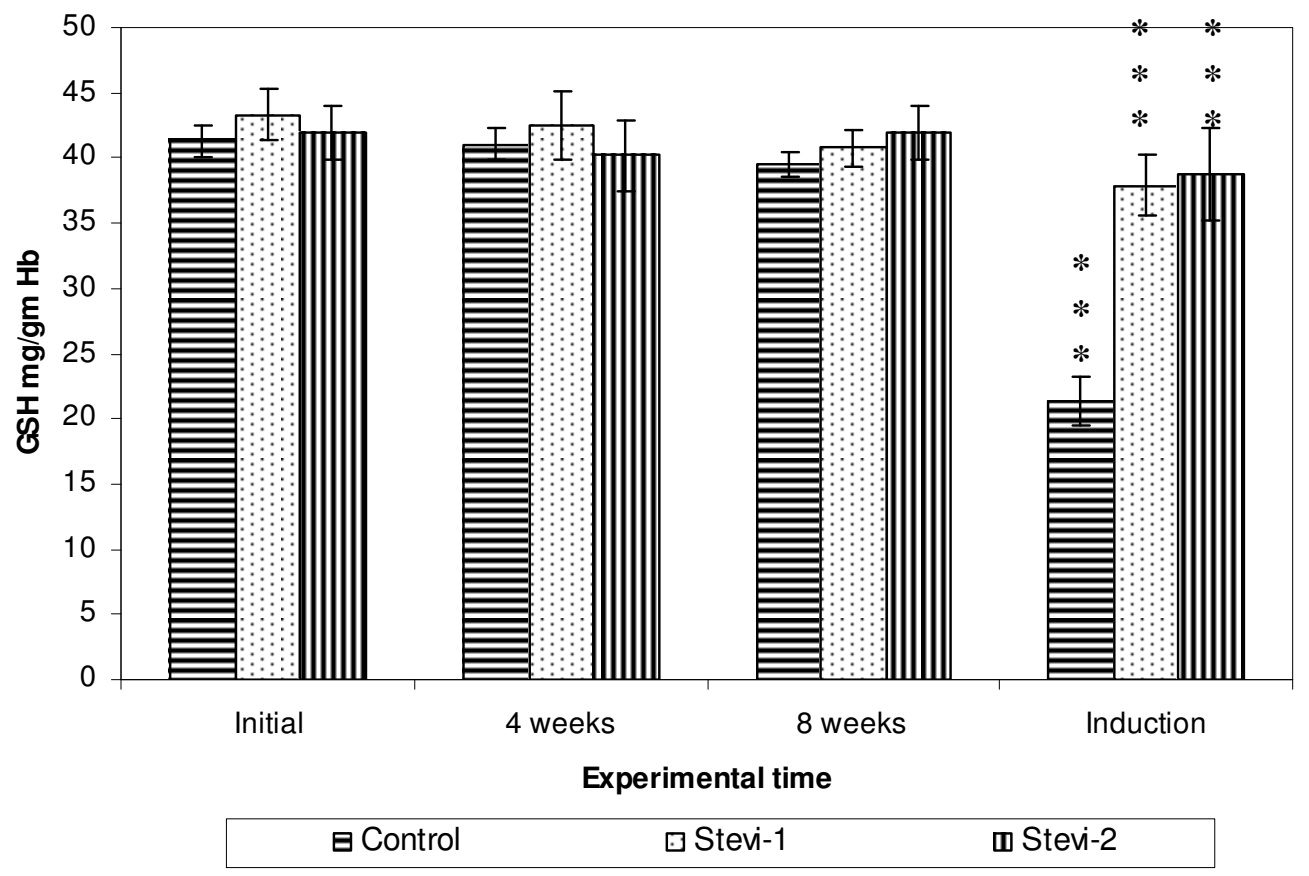

Fig.(4): The protective effect of stevioside preadministration for 8 weeks on reduced glutathione in whole blood (GSH) and after the inducton of hyperglycemia..

*** very highly significant difference for hyperglycemic control corresponding to normal level at $\mathrm{P}<0.001$

*** very highly significant difference for treatments corresponding to hyperglycemic level at $\mathrm{P}<0.001$

** highly significant difference for treatments corresponding to hyperglycemic level at $\mathrm{P}<0.01$ 


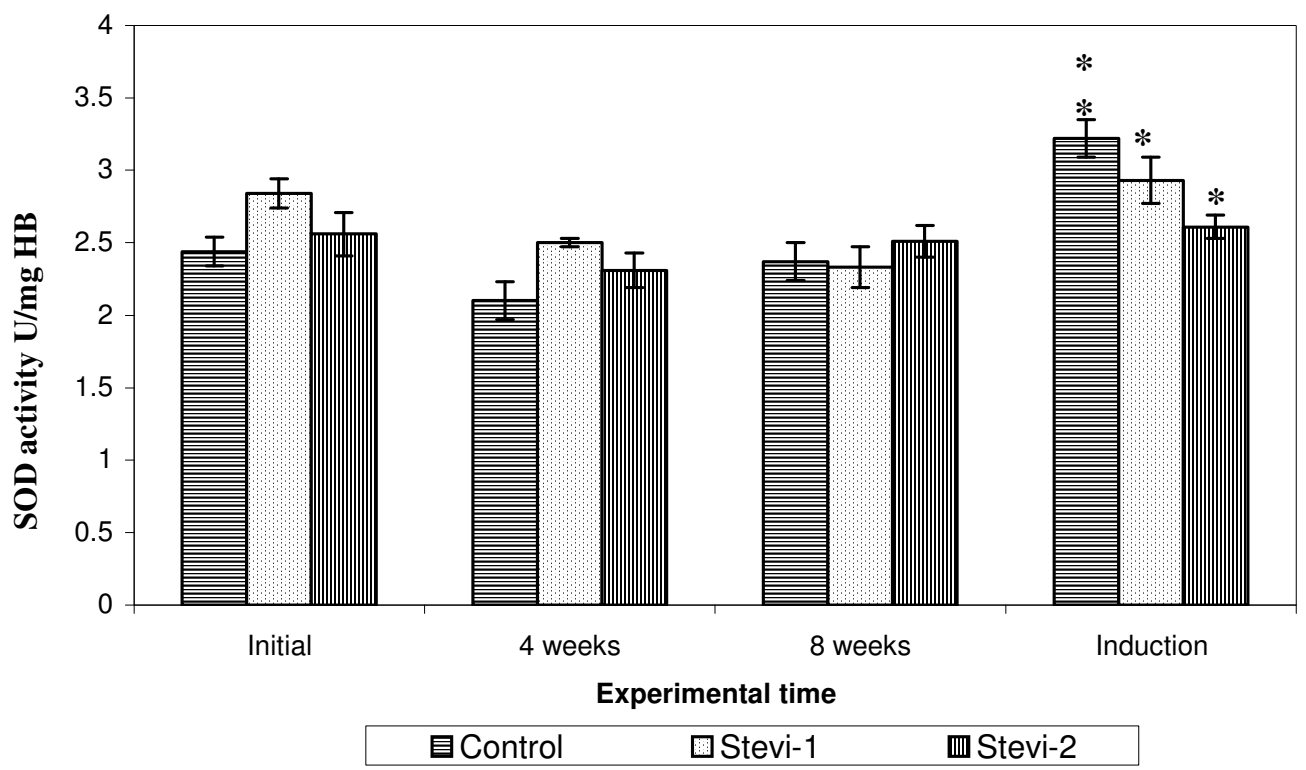

Fig.(5): The protective effect of stevioside preadministration for 8 weeks on superoxide dismutase, SOD, and after the induction of hyperglycemia..

** highly significant difference for hyperglycemic control corresponding to normal initial level at $\mathrm{P}<0.001$

* significant difference for treatments corresponding to hyperglycemic level at $\mathrm{P}<0.05$

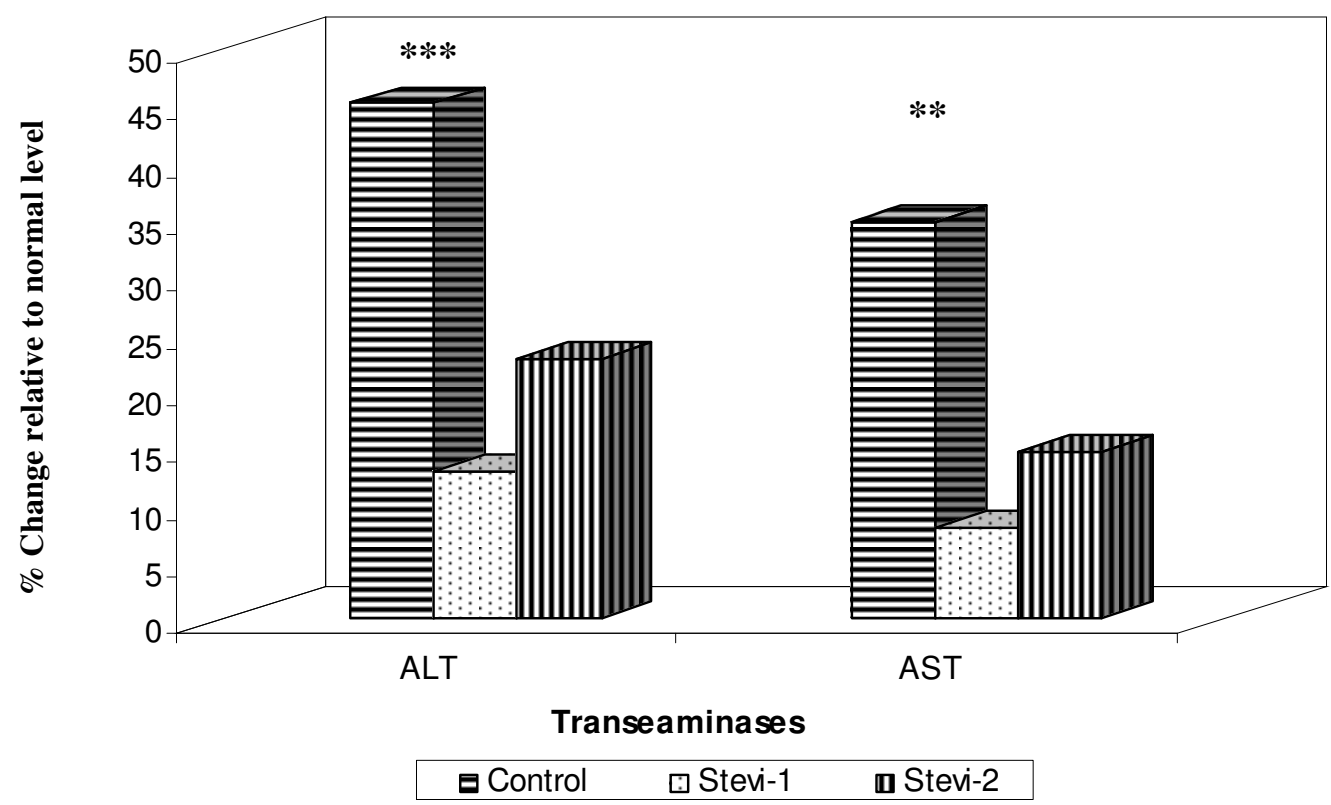

Fig.(6): The percent change occurred in the transsaminatses activity in both hyperglycemic and stevioside preadministrated rats in comparison with normal group.

**** very highly significant difference at $\mathrm{P}<0.001$

** highly significant difference at $\mathrm{P}<0.01$ 


\section{Stevioside as A low caloric sweetener to............}

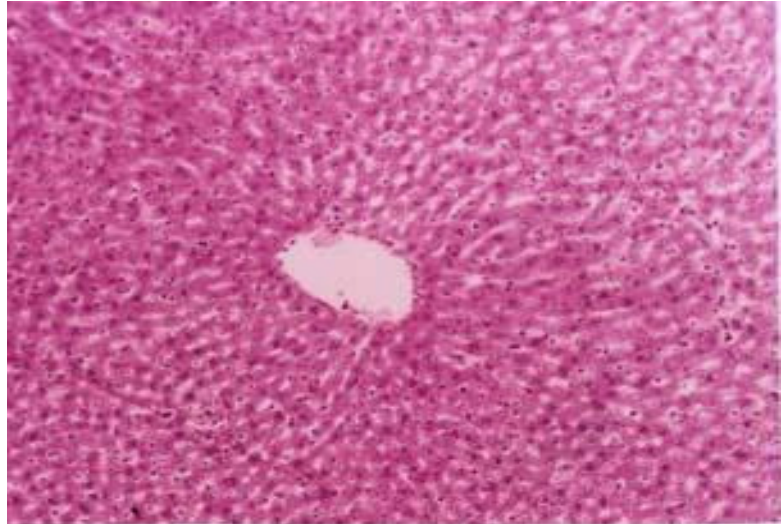

Fig 7: Section in a liver of rat treated with high dose stevioside, showed normal lobular archit-ecture, vacuolated hepatocytes could be seen at the periphery of the lobule.

[H \& E.,X 150]

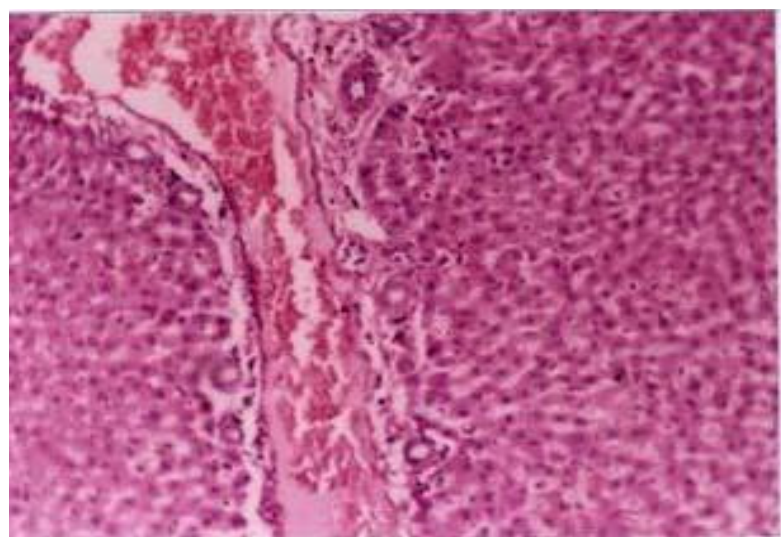

Fig. 9: Section in a liver of diabetic rat receive stevioside showed congested portal vein, thick hyalinized wall of arteriole and scattered inflammatory cells.

[ H \& E., X 150]

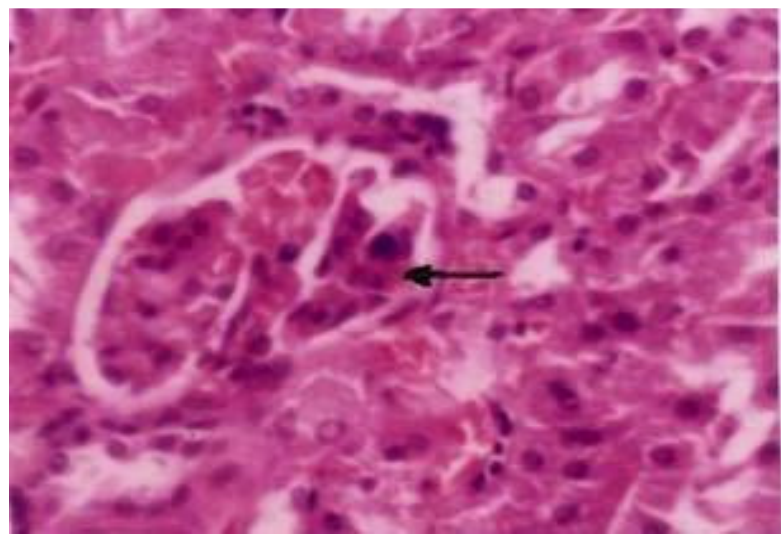

Fig. 11: Section in a kidney of diabetic rat showed hypertrophied and lobulated glomeruli, with focal sclerotic change (arrow)

[ H \& E., X 400]

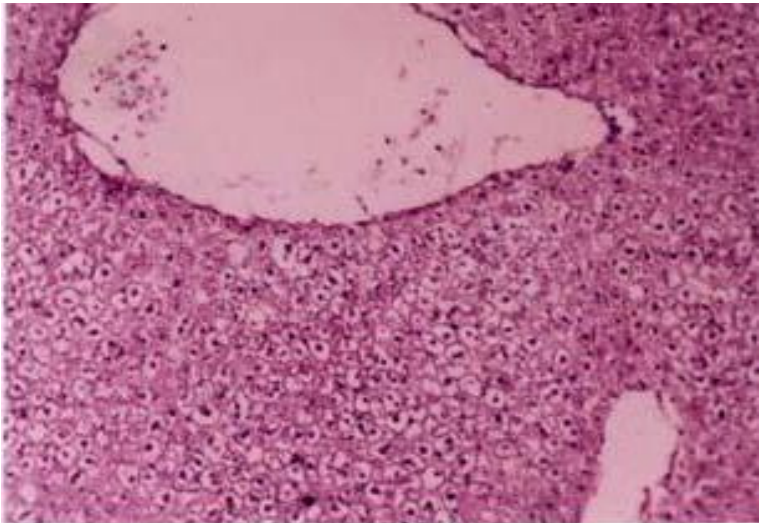

Fig.8: Section in a liver of rat received alloxan, showed highly vacuolated hepatocytes with atrophied nuclei and dilated central vein.

( H \& E. X 150]

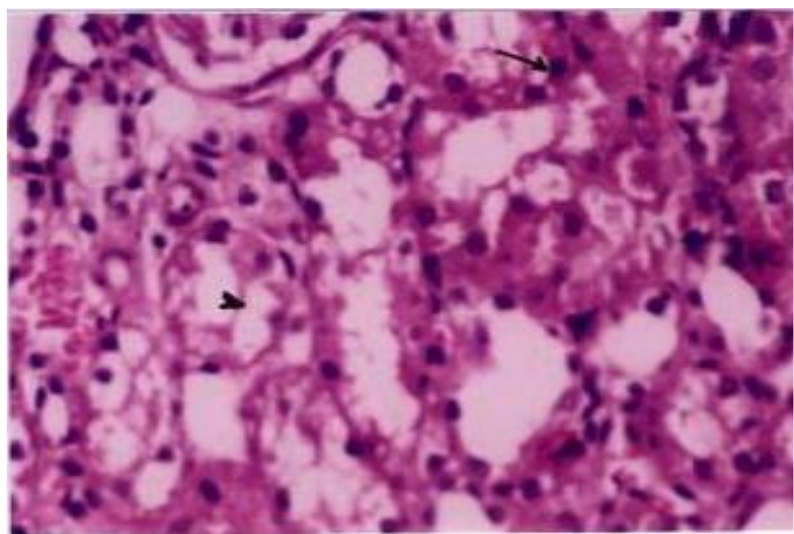

Fig.10: Section in a kidney of diabetic rat showed dilated proximal and distal convoluted tubules, darkely stained nuclei (arrow), signs of vacuolation (arrow head).

[ H \& E., X 400]

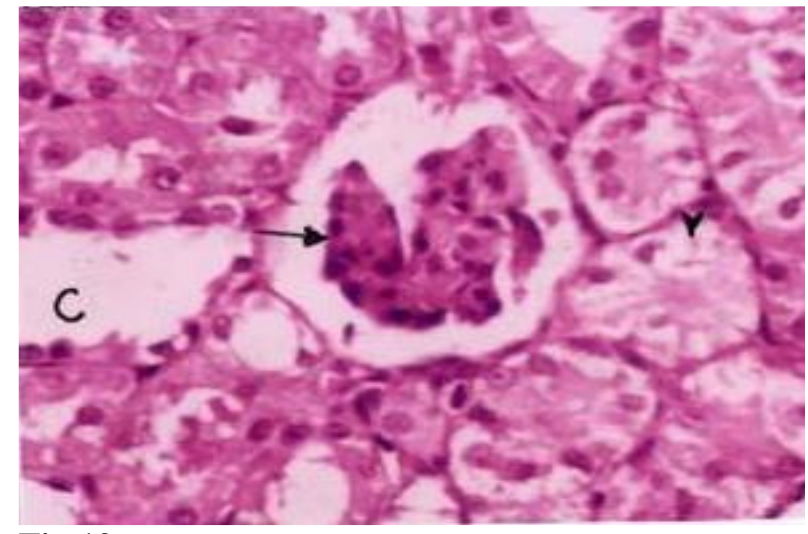

Fig.12:Section in a kidney of diabetic rat showed atrophied, lobulated glomeruli, with focal sclerotic change (arrow). The nuclei of proximal and distal convoluted tubules are faintely stained. Vacular degeneration (arrow head) and cystic change (C) were seen in renal tubular cells [ H \& E., X 400] 


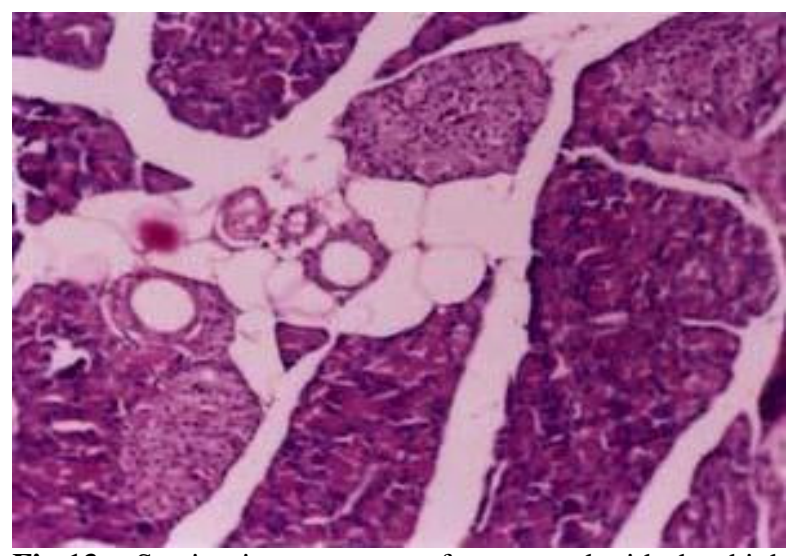

Fig 13a: Section in a pancreas of rat treated with the high dose of stevioside showed normal pancreatic islets and acini.

[ H \& E., X 150]

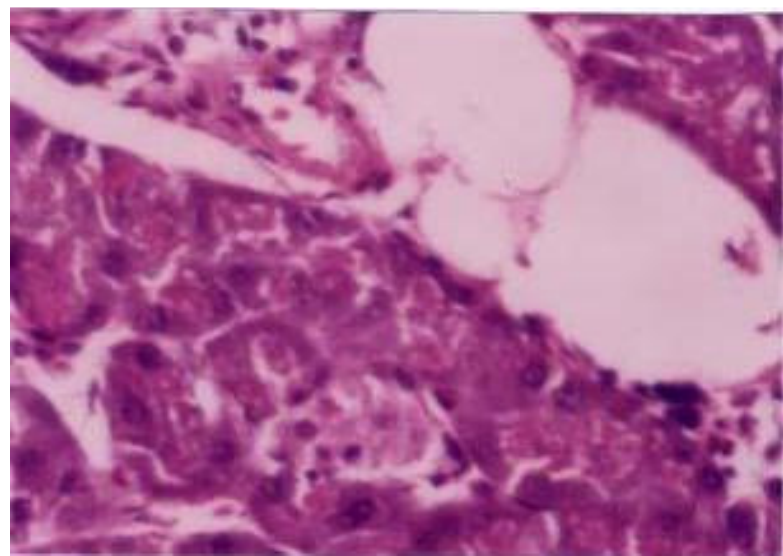

Fig 14: Section in a pancreas of diabetic rat showed marked reduction in size and cellularity of islets, scattered inflammatory cells was seen.,

[H \& E., X 400]

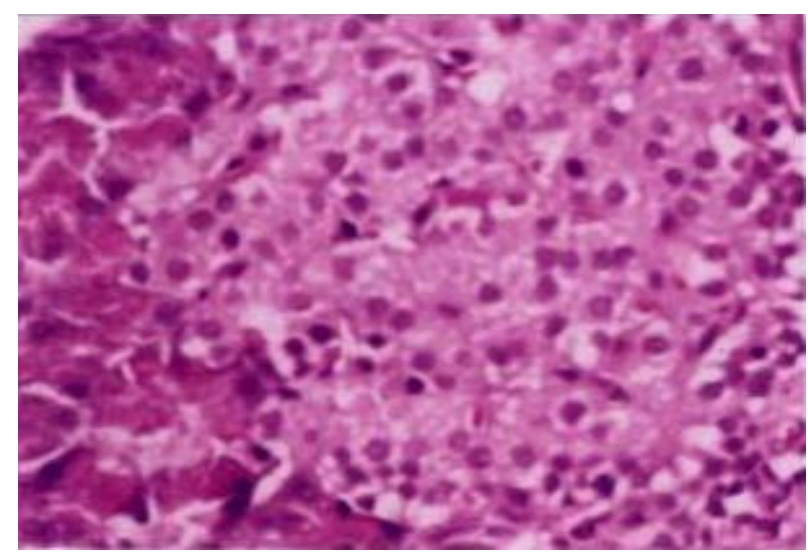

Fig. 13b: Section in a pancreas of rat treated with the low dose of stevioside showed normal pancreatic islets.

[H \& E., X 400]

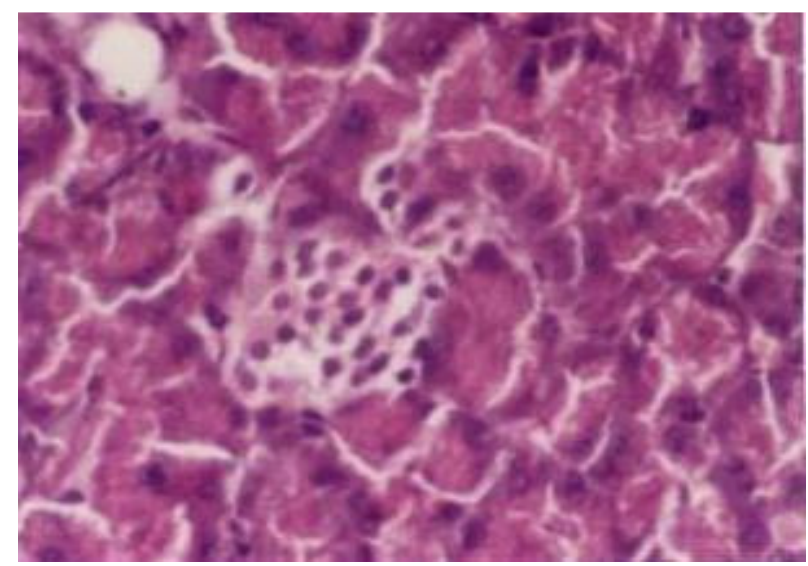

Fig. 15: Section in a pancreas of diabetic rat received the high dose of stevioside showed improvement in size and cellularity of islet. [ H \& E., X 400]

\section{Conclusion}

Stevioside is a potential natural product sweetener or food additive used for improving diabetes regulation. It reduces the rise in oxidative stress which exerted from the hyperglycemia and also has a safety additive for dairy product on the different organs under certain conditions.

\section{References}

1. Anonymous, (1980).Stevia components as sweetening and antibiotics.Jpn. Kokai Koho, 80 (92) : 323.

2. Barry, C. and Henry, A. (1981). Effect of Stevioside on the growth and acid production of Streptococcus mutanis. J. Dental Res., 60 : 430.

3. Bernstein, L. and Weatherall, M. (1952). Statistical for medical and other biological student, $2^{\text {nd }}$ ed., P.4955.

4. Beutler, E.; Duron, O and Kelly, B.M. (1963). Improved method for the determination of blood glutathione. J. Lab. Clin. Med., 61, 882-888.

5. Buege, J.A. and Aust, S.D. (1978). Methods enzymol. $12: 302-310$.

6. Chen, TH, Chen, SC, Chan, P, Chu, YL, Yang, HY and Cheng, J. (2005). Mechanism of the hypoglycemic effect of Stevioside, a glycoside of stevia rebaudian. Plant Med. Feb; 71 (2) : 108-13.

7. Collins, C.H. ; Patricia, M. Lyne and J.M. Grange (1989). Microbiological Methods. Sixth edition. Butterworths 
London Boston Singapore Sydney Toronto Wellington.

8. Curi, R., Alzarez, M, and Bazotte, R.B. (1986). Effect of Stevia rebaudiana on glucose tolerance in normal adult human. Braz. J. Biol. Res.; 19 : 771-774.

9. Dincer, $\mathbf{Y}$; Akcay, $\mathbf{T}$; Alademir, $\mathbf{Z}$ and Likova, H. (2002). Effect of antioxidative stress on glutathione pathway in red blood cells from patients with insulin dependent diabetes mellitus. Metabol., 51(10) : 1360.

10. El-Alfy, AT; Ahmed, AA and Fatani, A.J. (2005). Protective effect of red grape seeds proanthocyanidins against induction of diabetes by alloxan in rats. Pharmacol. Res., May 27.

11. Gregersen, S, Thomsen, JL and Brock, B. (1996). Endotheline-1-stimulates insulin secretion by direct action on the islets of langerhans in mice. Diabetologia; 39: 10301035.

12. Gregersen, S, Jappesen, PB, Holst, JJ and Hermansen, K. (2004). Antihyp-erglycemic effects of Stevioside in type 2 diabetic subjects. Metabolism. Jan; 53 (1) :73-6.

13. Gumieniczek, A. (2005). Effect of repaglinide on oxidative stress in tissues of diabetic rabbits. Exp. Toxicol Pathol. Mar:56 (45): 321-6.

14. Hayoz, D., Ziegler T, Brunner, HR and Ruiz, J. (1998). Diabetes mellitus and vascular lesions. Metabolism, 47, 16-19.

15. Hubler, MO, Bracht, $A$ and KelmerBracht, AM. (1994). Influence of Stevioside on hepatic glycogen levels in fasted rats. Res Commun. Chem. Pathol. Pharmacol. April, 84 (1): 111-8.

16. Kinghorn, AD, Soejarto, NPD and Nanayakkara, CM (1984). A phytochemical screening procedure for sweetentkaurene glycoside in the genus stevia. J. Nat. Prod.; 47 (3): 439-444.

17. Jeppesen, PB, Gregersen, $\mathbf{S}$ and Poulsen, CR (2000). Stevioside act directly on pancreatic Beta cells to secret insulin: Action independent of cyclic adenosine monophosphate and adenosine triphosphate-sensitive $\mathrm{K}^{+}$channel activity. Metabolism; 49: 208-214.

18. Jeppesen, PB, Gregersen, S, Alstrup, KK and Hermansen, K. (2002). Stevioside induces antihyperglycaemic, insulinotropic and glucagonostatic effects in vivo : studies in the diabetic Gots-kakizaki (GK) rats. Phytomedicine. Jan : 9 (1): 9-14.

19. Jeppesen, PB, Gregersen, $\mathbf{S}$ and Roefsen, SE (2003). Antihyperglycaemic and blood pressure-reducing effects of stevioside in diabetic Gots-kakizaki rat. Metabolism; 52: 372-378.

20. Lee, S.J. (1979). A study on the safety of stevioside as a new sweetening source. J. Food Sci. Technol., 11 : 224.

21. Madkour, M.K.; El-Allawy, R.M.M. ,Hamdy, M.M. and Awad, A.M. (1977). The effect of stevia pretreated on rats after oral glucose load. (glucose tolerance test GTT). J. Drug Res. Egypt., Vol. 9 No. 1-2 : 41-49.

22. Maier, V; Hermann, K. and Kienle, UDO (2003). Isolation Perfused Gut: Absorption of glucose is inhibited by Steviol, a degradation product of the sweetener Stevioside. American Diabetes Association Vol. 52 Supplements. June A 554.

23. Marklund, S. and Marklund, G. (1974). Involvement of the superosxide anion radical in the antioxidation pyrogallol and convenient assay for superoxide dismutase. Euro. J. Biochem., 17, 164-174.

24. Matsui, M, Matsui, $\mathbf{K}$ and Kawasaki, Y, (1996). Evaluation of the genotoxicity of Stevioside and steviol using six in vitro and one in vivo mutagenicity assays. Mutagenesis; 11 (6): 573-579.

25. Melis, MS (1992). Renal excretion of stevioside in rats. J. Nat. Prod.; 55(5): 688-690.

26. Rajbhandari,A and Roberts, MF. (1983). The flavonoids of Stevia Rebau-diana. J. Nat. Prod; 49:194-195.

27. Raskovic, A, Gavrilovic, M, Jakovljevic, V., Sabo, J. (2004). Glucose concentration in the blood of intact and alloxan-treated mice after pretreatment with commercial preparations of Stevia rebaudiana. J. Drug Metabolism Pharmacokinet. Apri. June; 29 )): 87-90.

28. Reitman, S. and Frankel, S. (1957). A colorimetric method for the determination of serum glutamic oxaloacetic and glutamic pyruvic transaminases. Am. J.Clin. Path., 221, (56): 56.

29. Raskovic, A, Gavrilovic, M, Jakovl, J. and Evie, V, Sabo, (2004). Glucose concentration in the blood of intact and alloxantreated mice after pretreatment with commercial preparation of stevia rebaudiana (2004). Eur. J. Drug Metab. Pharmacockinet. April-June; 29(2) 87-90.

30. Rosen, P, Dux and Teschope, D. (1998). Role of oxygen derived radicals for vascular dysfunction in the diabetic heart: prevention with $\alpha$-tocopherol. Mol. Cell Biochem., 188, 103-111.

31. Sabu, MC and Kuttan, R. (2004). Antidiabetic activity of Aegle mermelos 
and its relationship with its antioxidant properties. Indian J. Physiol. Pharmacol. Jan; 48 (1): 81-8.

32. Shibata, H, Sawa, Y and Oka, T (1995). Steviol and Steviol-glycoside: Glucosyl transferase activities in Stevia rebaudiana Bettoni-purification and partial characterization. Arch Biochem. Biophys.; 321 (2): 390-396.

33. Soejarto, DD, Douglas, K, and Farnsworth, NR (1982). Potential sweetening agents of plant origin III. Organoleptic evaluation of Stevia leaf herbarium samples for sweetness. J.Nat. Prod.; 45 (5): 590-599.

34. Stoon, AE (2002). The top functional food trends. The next generation. Food Technology, 56; 32.

35. Suzuki, H.; Kasai, T.; Sumiahara, M. and Sujisawa, H. (1977). Influence of the oral administration of stevioside on the levels of blood glucose and liver glycogen in intact rats. Nogyo Kagaku Zasshi, 51 (3) $: 45$.

36. Szaleczky, E, Prechl, F. J and Somogyi, A. (1999). Alterations in enzymatic antioxidants defence in diabetes mellitus- a rational approach. Postgrad. Med. J., 75, 13-17.

37. Tomita, T; Sato, N; Arai, T; Shiraishi, H; Sato, M; Takeuchi, M. and Kamio, Y.
(1997). Bactericidal activity of a fermented hot-water extract from Stevia rebaudiana Bertoni towards enterohemorrhagic Echerichia coli O 157:H7 and other foodborne pathogenic bacteria. Microbiol. And Immunol., 41 (12) 1005.

38. Toskulko, C, Chaturat, L, Temcharoen, $P$ and Glinsukon, T. (1997). Acute toxicity of stevioside, a natural sweetener and its metabolic steviol, in several animal species. Drug Chem. Toxicol., 20 (1-2): 31-44.

39. Trinder, P. (1969). Determination of blood glucose using an oxidase-peroxidase system with or non carcinogenic chromogen. (C.F. Chem. Abst., 70 : 11254h).

40. Van Kampen, E.J. and Zijlstra, W.G. (1967). International Committee for Standardization in Haematology. British Journal Haematology 13 (suppl), 71, Chim. Acta., 6:538-544.

41. Yadav, P; Sarkar, S and Bhatnagar, D. (1997). Action of Capparis deciaduas against alloxan induced oxidative stress and diabetes in rat tissues. Pharmacol. Res., 36 (3) 221.

42. Yinic, X.; Toshiyasu, Y.; Mintu, S. and Masaaki, T. (1998). Study on stevia rebaudiana for antioxidant activity. Vippon Shokuhin Kagaku. Kogaku Kaishi, 45 (5): 310. 
إضافة مادة الاستيفيوسيد إلى اللبن كمحلى طبيعي منخفض السعرات الجئ ودوره الوقائي ضد الثوارد الحرة في الجرذان المصنية كابة بارتفاع سكر الام

أيمن محمد بدوي" ، نادية عبد الله الطبلاوي" ، ناهد صادق باسيلي **، سامي

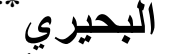

* شعبة الكيمياء الحيوية ** شعبة در اسة الأنسجة *** شعبة التقييم الغذائي و علوم الأغذية

الهيئة القومية للرقابة و البحوث الدو ائية.

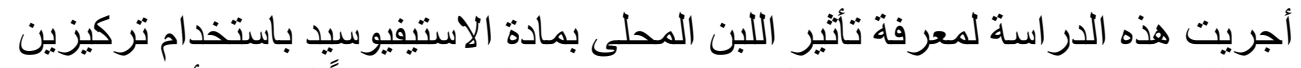

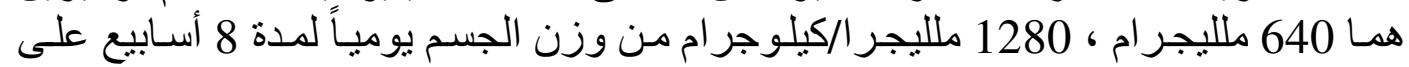

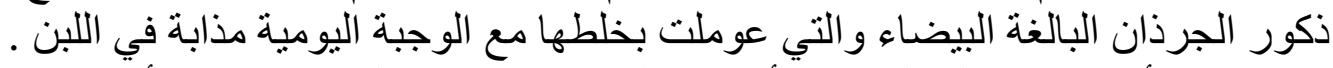

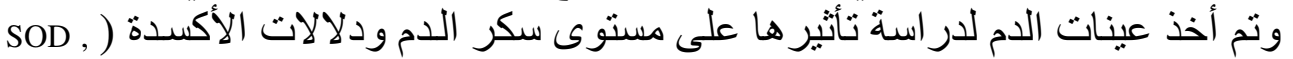

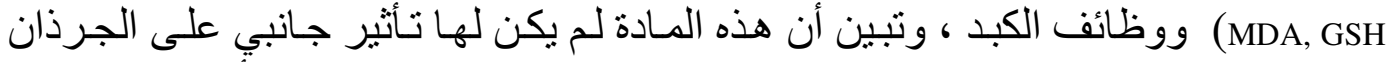

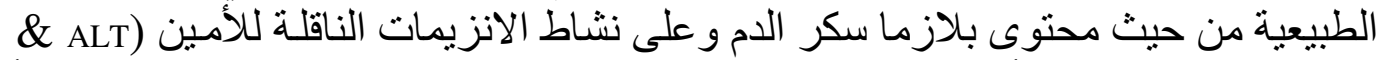
(AST

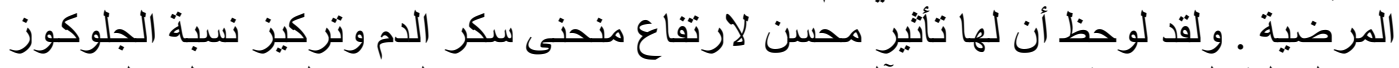

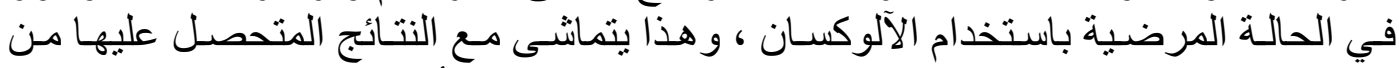

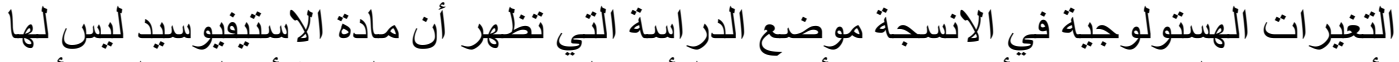

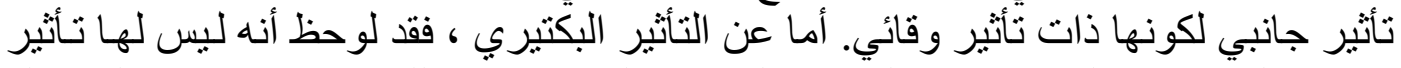

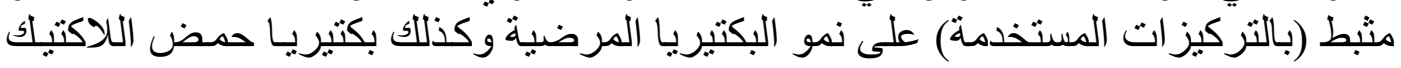
المستخدمة في الصناعات اللبنية. 